\title{
Cancer-related psychosocial factors and self-reported changes in lifestyle among gynecological cancer survivors: cross sectional analysis of PROFILES registry data
}

Karin A. J. Driessen

Netherlands Comprehensive Cancer Organisation

Belle H. de Rooij

Netherlands Comprehensive Cancer Organisation

M. Caroline Vos

Elisabeth-TweeSteden Ziekenhuis

Dorry Boll

Catharina Ziekenhuis

Johanna M.A. Pijnenborg

Radboudumc

Meeke Hoedjes

Tilburg University

Sandra Beijer

Netherlands Comprehensive Cancer Organisation

Nicole PM Ezendam ( $\sim$ n.ezendam@iknl.nl)

Netherlands Comprehensive Cancer Organisation; Tilburg University https://orcid.org/0000-0002-5878-4210

\section{Research Article}

Keywords: Cancer Survivors, Gynecology, Health Behavior, Diet, Exercise, Psychosocial Factors

Posted Date: February 12th, 2021

DOI: https://doi.org/10.21203/rs.3.rs-216269/v1

License: (c) (i) This work is licensed under a Creative Commons Attribution 4.0 International License. Read Full License

Version of Record: A version of this preprint was published at Supportive Care in Cancer on August 28th, 2021. See the published version at https://doi.org/10.1007/s00520-021-06433-0. 


\section{Abstract}

Purpose: Obesity is prevalent in gynecological cancer survivors and is associated with impaired health outcomes. Concerns due to cancer and its treatment may impact changes in lifestyle after cancer. This study aimed to assess the association between cancer-related psychosocial factors and changes in physical activity and diet, 18 months post-diagnosis among gynecological cancer survivors.

Methods: Cross-sectional data from the ROGY care study were used, including endometrial and ovarian cancer patients treated with curative intent. The impact of cancer scale (IOCv2) was used to assess cancer-related psychosocial factors. Self-reported changes in nutrients/food groups and in physical activity post-diagnosis were classified into change groups (less/equal/more). Multivariable logistic regression models were used to assess associations.

Results: Data from 229 cancer survivors (59\% endometrial, $41 \%$ ovarian, mean age $66 \pm 9.5$,

$70 \%$ tumor stage I) were analyzed. In total, $20 \%$ reported to eat healthier from diagnosis up to 18 months postdiagnosis, $17 \%$ reported less physical activity and $20 \%$ more physical activity. Health awareness, body change concerns, life interferences and worry were significantly associated with less physical activity up to 18 months postdiagnosis whereby gastrointestinal symptoms were an important confounder.

Conclusion(s): This study underlines the need to raise awareness of the benefits of a healthy

lifestyle and to provide tailored lifestyle advice, taking into account survivors'

health awareness, body change concerns, life interferences, worry and gastrointestinal

symptoms, in order to improve health behavior among gynecological cancer survivors.

Trial Registration: clinicaltrials.gov Identifier: NCT01185626, August 20, 2010

\section{Introduction}

The development of endometrial cancer and (to a smaller extent) ovarian cancer, can be attributed to consequences of obesity in many cases. Consequently, obesity prevalence rates are high in survivors of endometrial (45-70\%) and ovarian $(30 \%)$ cancer [1,2]. Moreover, removal of the ovaries is part of standard surgical treatment in gynecological cancer and has been associated with increased visceral fat accumulation and body fatness [3]. Obesity has been associated with impaired quality of life developing health problems (e.g. cardiovascular disease) and worse overall survival $[2,4-6]$. To reduce obesity it is important to promote physical activity and healthy dietary behavior [7].

A cancer diagnosis has been suggested to be a 'teachable-moment' which has the potential to motivate patients to make healthy lifestyle changes [8]. Even though $30-60 \%$ of cancer survivors change their lifestyle post-diagnosis, adherence to recommendations for physical activity and diet remains relatively low as compared with the cancerfree population $[9,10]$. Moreover, adherence to recommendations among cancer survivors has been found to decrease over time [11]. These findings suggest that efforts are needed to encourage healthy behavior among cancer survivors.

According to theories and models of health behavior change, such as the Health Belief Model (HBM), perceived barriers, such as fatigue, decreased physical functioning and body image concerns, have shown to be important 
aspects in explaining behavior (change) [12,13]. In addition, fear and worry for cancer recurrence have been related to intentions to change health [14]. In line with the HBM, people who perceive susceptibility to a particular health problem have been shown to be more likely to engage in risk-reducing health behavior [13]. On the other hand, distress has been related to unhealthy behavior, possibly due to negative coping strategies [14]. Furthermore, increased sense of meaning or purpose, may increase health awareness, which is a prerequisite for behavior change, while posttraumatic growth may be a cue to action, as described in the HBM [13,15-17].

Current studies explaining health behavior change after cancer diagnosis focus on more general aspects including socio-demographic factors, clinical variables or cognitive behavioral factors $[9,14,18,19]$. These studies neither focus on change of health behavior comparing pre-diagnosis nor distinguish associations of factors with physical activity and diet $[9,14,18,19]$. Insight into associations between cancer-related psychosocial factors and lifestyle changes may help identifying factors that may explain engagement in health behavior change. This will contribute to development of more targeted lifestyle interventions to promote health behavior change among cancer survivors. Therefore, this study aims to examine the association between cancer-related psychosocial factors and changes in lifestyle 18 months post-diagnosis among gynecological cancer survivors.

\section{Methods}

Study design

This study is a secondary cross-sectional analysis of data from the ROGY care trial [20].The ROGY care trial is a pragmatic, cluster randomized controlled trial that aimed to assess the effect of a Survivorship Care Plan (SCP) on information provision and post-treatment care for cancer patients [20]. Data from both trial arms were analyzed together, as it is assumed that the SCP did not affect lifestyle because it did provide minimal information on lifestyle. The questionnaire administered at 18 months post-diagnosis was used for the purpose of this study. The study was approved by the Medical Research Ethics Committee [20].

Study population and data collection

Eligibility criteria to participate in the ROGY Care trial were (1) newly diagnosed patients with either primary endometrial or ovarian cancer between April 2011 and October 2012, (2) curative treatment, (3) aged $\geq 18$ years, and (4) being able to complete a Dutch questionnaire. In total, 544 participants ( $N=296$ endometrial, N=248 ovarian) were eligible and $73 \%$ responded ( $\mathrm{N}=221$ endometrial, $\mathrm{N}=174$ ovarian) to the baseline questionnaire (Online Resource 1). A total of 230 participants ( $\mathrm{N}=137$ endometrial, $\mathrm{N}=93$ ovarian) completed the questionnaire at 18 months (response of $42 \%$ from eligible participants for the study) [20].

Measures

Cancer-related psychosocial factors

The validated Impact of Cancer scale version 2 (IOCv2) was used to assess cancer-related psychosocial factors [21]. For each of the subscales: health awareness, meaning of cancer, appearance concerns, body change concerns, life interferences and worry (including items scored on a five-point Likert scale) a sum score was calculated. The item 'having had cancer has made me take better care of myself' from the subscale health awareness was excluded from the analysis as Cronbach's alpha improved when excluding this item (from 0.79 up to 0.84). Furthermore, it 
was strongly related to our dependent variables (change in lifestyle). Internal consistency (Cronbach's alpha) for each of the subscales was good (ranging from/ range 0.83-0.93).

Changes in dietary behavior and physical activity

By use of self-developed questionnaires from the PROFILES registry studies, participants reported if they made changes in diet since they were diagnosed with cancer (yes/no) until 18 months post-diagnosis [22]. If so, they reported their most important changes (more/ less) in diet (fat, meat, fish, vegetables, fruit, milk and dairy products, dietary fibers/whole grain products, sugar, alcohol, water, salt and 'others') since diagnosis. Changes were classified in healthy (more consumption of fruit, vegetables, fibers/wholegrain and less consumption of fat, meat, sugar, alcohol and salt) or unhealthy (vice versa) according to the World Cancer Research Fund (WCRF) recommendations [23]. If respondents reported more healthy changes than unhealthy changes, they were classified into the eating healthier ( $\mathrm{N}=44)$ group and if they reported more unhealthy changes, as many unhealthy as healthy changes or no change, they were classified into the no change/eating unhealthier $(\mathrm{N}=172)$ group. As only few participants made unhealthy choices $(\mathrm{N}=9)$ these individuals were grouped with the no change group.

Furthermore, participants reported if they made changes in their physical activity since they completed their cancer treatment (yes/no) compared to pre-diagnosis. If so, they reported if they increased or decreased a certain type of physical activity (walking, cycling, gardening, housekeeping, sports and others). Subsequently, respondents were classified into the group: no change in physical activity $(\mathrm{N}=133)$, more physical activity $(\mathrm{N}=43)$ or less physical activity ( $\mathrm{N}=36)$, according to the amount of reported decreases or increases in physical activity (despite differences in intensity of activities).

\section{Socio-demographic and clinical factors}

Factors obtained from the Netherlands Cancer Registry were age and socio-economic status (based on postal code of the residence area of the patient, categorized into low/ intermediate vs. high) and clinical factors (cancer type: ovarian/endometrial; tumor stage: I vs. II, III or IV; type of treatment: surgery, radiotherapy and chemotherapy; amount of comorbidities: $0,1,>1$ ) [24]. Self-reported questionnaires included marital status (married/living together vs. divorced, widowed, never married/never lived together), educational level (low, intermediate, high) and physical limitations in daily activities (scored as 100 minus score of the EORTC QLQ-C30 physical functioning scale) [25] .Body Mass Index (BMl; weight in kg/length in $\mathrm{m}^{2}$ ) at 18 months post-diagnosis was based on self-report. Reasons for change in physical activity included complaints related to cancer or its treatment (not further specified), support of physical recovery, prevention of cancer recurrence and other reasons. Furthermore, participants were asked whether they received advice (yes/no) regarding diet (and/or dietary supplements) and/or physical activity, from diagnosis up to 18 months thereafter (provider or moment of received advice was not further specified). Gastrointestinal (GI) symptoms were obtained from a questionnaire developed by a dietitian from our research team and included unintentional weight loss or gain, poor appetite, cramps, frequent small amounts of stool, constipation, diarrhea, change in taste and/or smell, aversion, acid reflux and others. Unintentional weight loss and weight gain were excluded and a sum score (range 0-11) was based on the number of symptoms (suffered in the past or still suffering).

\section{Statistics}

Descriptive data was reported by means and standard deviations (SDs) or medians and interquartile ranges (IQRs) (continuous variables), frequencies and percentages (dichotomous and categorical variables) and compared by use 
of t-tests, ANOVA with post-hoc procedures, Mann-Whitney U and Kruskal-Wallis tests (continuous variables) and Chi-square/Fisher's Exact tests (categorical variables).

Statistical analyses were performed by SAS for Windows (version 9.4). Associations between psychosocial factors as independent variables (i.e. sum scores from the scales health awareness, meaning of cancer, appearance concerns, body change concerns, life interferences, worry (range 1-5)), and dietary changes (no change/eating unhealthier (reference)/ eating healthier) or physical activity changes (no change(reference)/less/more) as dependent variables, were analyzed with logistic regression models. Before analyzing the data, assumptions were checked and not violated. P-values $<0.05$ were considered as statistically significant.

Potential confounders were age, socio-economic status, partner status, cancer type, tumor stage,treatment, number of comorbidities, BMI, gastrointestinal symptoms and physical limitations since these have been associated with psychosocial well-being as well as health behavior $[9,19,21,26,27]$. Variables gastrointestinal symptoms (sum score, 0-11) and physical limitations were considered as confounders prior to analysis. Other variables were considered to be a confounder when it caused a relevant change (a minimum of 10 percent) in the regression coefficient in the univariate model [28]. By hierarchical regression, the relevant confounders (determined per subscale) were added to the univariate model in the first step. Subsequently, the variable gastrointestinal symptoms was added to all models and the variable physical limitations was added to the physical activity change models.

\section{Results}

In total, 229 participants were included in the analyses as they responded on any of the outcome variables (Table 1). Participants were on average 66 years, $59 \%$ were diagnosed with endometrial cancer and $77 \%$ had one or more comorbidity. In total, $80 \%$ of participants responding to dietary behavior questions $(\mathrm{N}=216)$ reported not having changed their diet $(\mathrm{N}=169)$ or made unhealthier changes $(\mathrm{N}=3)$ and $20 \%(\mathrm{~N}=44)$ reported healthier changes in diet. For physical activity, $63 \%(\mathrm{~N}=133)$ of participants responding on physical activity questions ( $\mathrm{N}=212)$ reported not having changed their physical activity level after treatment, $17 \%(\mathrm{~N}=36)$ reported less physical activity and $20 \%$ $(\mathrm{N}=43)$ more physical activity.

The most common reported reason for decreased physical activity levels was complaints related to cancer (treatment) $(44 \%, \mathrm{~N}=16)$. In de group that became more physically active, important reasons were support of physical recovery $(65 \%, \mathrm{~N}=28)$, prevention of cancer recurrence $(19 \%, \mathrm{~N}=8)$ and other reasons $(19 \%, \mathrm{~N}=8)(\mathrm{e} . \mathrm{g}$. for weight loss, to relax, for fun) (not tabulated).

From the total population $57 \%(\mathrm{~N}=129)$ received no advice. The groups that did not change their diet or physical activity, more often received no advice $(62 \% \mathrm{~N}=107$ and $68 \% \mathrm{~N}=90)$. From all groups, survivors who became less physically active since diagnosis received the most advice regarding diet $(14 \%, N=5)$, physical activity $(33 \%, N=12)$ and combined (31\%, N=11) (Online Resource 2).

A higher health awareness (OR 2.79, 95\% Cl: 1.38; 5.65), body change concerns (OR $3.0495 \%$ Cl: 1.71; 5.39), life interferences (OR $4.8895 \%$ 2.29; 10.38) and worry (OR 2.62, 95\% Cl: 1.42; 4.85) was associated with less physical activity, compared to 'no change', after adjustment for confounders (Table 3). In all associations, gastrointestinal symptoms were found to be a stronger confounder (but associations remained significant) compared with physical limitations (data not shown). The psychosocial factors were not associated with changes in diet (Table 2) or more physical activity (Table 3). 


\section{Discussion}

The results of this cross-sectional study indicate that the majority of gynecological cancer survivors does not improve their lifestyle after diagnosis. In contrast to favorable changes in diet or physical activity, reported decreases in physical activity were associated with cancer-related complaints. Participants who report a higher health awareness, more body change concerns, more life interferences and more worry seem to be at risk to become less physically active compared with pre-treatment up to 18 months post-diagnosis. These findings are not in line with health behavior change theories, suggesting that being aware of health problems and perceiving susceptibility for health problems motivates people to engage in positive health behavior [16]. This might be explained by the use of maladaptive coping strategies (i.e. avoidance or disengagement), as these have shown to be commonly used by cancer survivors [29]. Cancer survivors focusing on their limitations and losses (i.e. higher health awareness, body change concerns and life interferences) may use a passive coping strategy, resulting in less physical activity. In addition, it has been suggested that psychological distress (including worries) is also associated with maladaptive coping responses and engaging in unfavorable health behavior [14,30].

Furthermore, we found a relatively small proportion of cancer survivors making healthy changes in diet (20\%) and/or physical activity (20\%), in contrast to other studies [9,31]. This might be explained by the fact that majority $(57 \%)$ of participants received no advice regarding diet and physical activity. As there is no information on the provider and content of the advice given in the current study, it is unclear whether beneficial effects of a healthy lifestyle related to the risk of developing health problems were discussed. However, it is likely that participants receiving advice are more aware of these beneficial effects compared to participants receiving no advice and therefore were more likely to make positive health behavior changes [32]. This seems in contrast to our finding that participants reporting less physical activity, more often received advice regarding physical activity, compared to other change groups. However, participants who received advice also had more physical limitations, gastrointestinal symptoms and higher impact of cancer scores compared to survivors who did not receive advice (data not shown) which might explain this unexpected finding, assuming that only participants 'at risk' received advice which is also the group having the greatest effort to increase their physical activity.

Furthermore, finding no associations between psychosocial impact and favorable health behavior changes might be explained by the fact that perceived benefits of physical activity were associated with increased physical activity levels instead of perceived susceptibility to health problems [33]. If survivors did not believe (or were not aware) that health behavior is important in reducing the risk of health problems, they might not change their health behavior, even if they are worried about their health or future [34].

Furthermore, associations were partly determined by the presence of gastrointestinal symptoms, as they were an important confounder. These symptoms are known side-effects of cancer treatment that sometimes rarely improve by time or even become chronic symptoms [35]. Taking into account that suffering from physical complaints (in general) was a frequently reported reason to be less physically active, attention for the potential role of (physical) complaints as a barrier in health behavior changes after cancer (treatment), is recommended. Lifestyle changes can contribute to treating complaints (e.g. physical activity in case of cancer-related fatigue) or prevent unnecessary deterioration of complaints (e.g. diet in case of bowel dysfunction) [27]. Thus, besides the importance of lifestyle advice as a motivator for engagement in healthy behavior, it has also an important role in coping with complaints and prevention of deterioration of their current lifestyle. 
To the best of our knowledge, our study was the first to focus on the psychological impact of cancer in associations with both physical activity and diet in gynecological cancer survivors. Furthermore, participants were recruited by population-based sampling and a validated scale was used to examine the psychosocial impact of cancer [21].

An important limitation of this study is that we did not have information on the magnitude and specific content of the changes in diet (e.g. amount and macronutrients) and physical activity (e.g. intensity and duration). As participants were asked to report their most importantchanges in diet, changes were assumed to be from noteworthy size.

In addition, data on diet and physical activity was self-reported by respondents which could have led to socially desirable answers and recall errors. The absence of reported unhealthy changes in diet may reflect this bias. Furthermore, due to the small sample size, models could be adjusted for a maximum of two confounders to be able to analyze models with sufficient power. In addition, participants differed by age, educational level and tumor stage compared to lost to follow-up, possibly affecting some response bias [30]. Finally, we were not able to correct for physical complaints (except gastrointestinal symptoms) due to cancer (treatment) or for received lifestyle advice. As the majority of the participants mentioned that complaints related to cancer or its treatment were a reason to change physical activity levels, this is a potential confounder.

Given the benefits of a healthy lifestyle in prevention of (other) health problems, survivors should be encouraged to live healthier. Without receiving advice, a gynecological cancer diagnosis is less likely to be utilized as a 'teachable moment' by cancer survivors, with regard to making healthy changes in lifestyle. For tailored lifestyle advice, oncologists (or oncology nurses) should identify survivors concerns and worries about their health and physical complaints (e.g. gastrointestinal symptoms) that may be barriers for engagement in health behaviour and refer to other healthcare professionals if necessary. For further research, it is highly recommended to use a longitudinal study design a larger sample, and objective measurement of diet and physical activity (e.g. using nutritional diaries and accelerometers). Finally, a qualitative approach can be used to gain insight into survivors' beliefs about lifestyle related to developing health problems, their coping strategies with cancer related worries/concerns and their barriers for engagement in health behaviour.

In conclusion, the results suggest that improving lifestyle after diagnosis is not self-evident for gynecological cancer survivors. Some even become less physically active which was associated with complaints, that requires attention and support of oncologists. Being more aware of health, having more concerns about body changes, experiencing more life interferences and worrying more about their future or health, was found to be associated with a self-reported decrease in physical activity from diagnosis up to 18 months. This study underlines the need to emphasize the benefits of a healthy lifestyle by oncologists. Moreover, oncologists should provide tailored lifestyle advice taking into account survivors' health awareness, body change concerns, life interferences, worry and gastrointestinal symptoms, in order to improve health behaviour.

\section{Declarations}

\section{Funding:}

The ROGY Care trial is supported with grant no. UVT 2010-4743 from the Dutch Cancer Society.

\section{Conflict of interest:}


The authors declare that they have no conflict of interest.

Ethics approval: Approval for the ROGY Care trial was obtained from the Medical Ethical Research Committee St. Elisabeth Hosipital (NL33429.008.10), the Netherlands. The study has been conducted in accordance with the 1964 Helsinki Declaration.

Consent to participate: Written informed consent was obtained from all individual participants in the ROGY care trial.

Consent for publication: all authors provided consent to publish the final submitted version

Availability of data: Data is available for non-commercial use upon request (www.profilesregistry.nl)

Code availability: Statistics code is available for non-commercial use upon request

\section{Author Contributions:}

Karin Driessen: conceptualization, methodology, formal analysis, investigation, data curation, writing: original draft, writing: review and editing. Belle de Rooij: supervision, conceptualization, methodology, formal analysis, investigation, data curation, writing: review and editing. M. Caroline Vos: investigation, writing: review and editing. Dorry Boll: investigation, writing: review and editing. Johanna Pijnenborg: investigation, writing: review and editing. Meeke Hoedjes: investigation, writing: review and editing. Sandra Beijer: methodology, investigation, writing: review and editing. Nicole Ezendam: supervision, conceptualization, methodology, formal analysis, investigation, data curation, writing: review and editing.

\section{References}

1. Beesley VL, Eakin EG, Janda M, Battistutta D (2008) Gynecological cancer survivors' health behaviors and their associations with quality of life. Cancer Causes Control 19 (7):775-782. doi:https://10.1007/s10552-008-9140y

2. Oldenburg CS, Boll D, Nicolaije KA, Vos MC, Pijnenborg JM, Coebergh J-W, Beijer S, van de Poll-Franse LV, Ezendam NP (2013) The relationship of body mass index with quality of life among endometrial cancer survivors: a study from the population-based PROFILES registry. Gynecol Oncol 129 (1):216-221. doi:https://10.1016/j.ygyno.2012.12.041

3. McCarthy AM, Menke A, Visvanathan K (2013) Association of bilateral oophorectomy and body fatness in a representative sample of US women. Gynecol Oncol 129 (3):559-564. doi:https://10.1016/j.ygyno.2013.02.016

4. von Gruenigen VE, Tian C, Frasure H, Waggoner S, Keys H, Barakat RR (2006) Treatment effects, disease recurrence, and survival in obese women with early endometrial carcinoma: a Gynecologic Oncology Group study. Cancer 107 (12):2786-2791. doi:https://10.1002/cncr.22351

5. Ward KK, Shah NR, Saenz CC, McHale MT, Alvarez EA, Plaxe SC (2012) Cardiovascular disease is the leading cause of death among endometrial cancer patients. Gynecol Oncol 126 (2):176-179. doi:https://10.1016/j.ygyno.2012.04.013

6. Smits A, Smits E, Lopes A, Das N, Hughes G, Talaat A, Pollard A, Bouwman F, Massuger L, Bekkers R (2015) Body mass index, physical activity and quality of life of ovarian cancer survivors: time to get moving? Gynecol Oncol 139 (1):148-154. doi:https://10.1016/j.ygyno.2015.08.005 
7. Pasanisi F, Contaldo F, De Simone G, Mancini M (2001) Benefits of sustained moderate weight loss. Nutr Metab Cardiovasc Dis 11:401-406

8. Bell K (2012) Remaking the self: trauma, teachable moments, and the biopolitics of cancer survivorship. Cult Med Psychiatry 36 (4):584-600. doi:https://10.1007/s11013-012-9276-9

9. Ghelfi F, Tieri M, Gori S, Nicolis F, Petrella M, Filiberti A, Apolone G, Titta L (2018) Do cancer patients change their diet in the e-health information era? A review of the literature and a survey as a proposal for the Italian population. Food Res Int 104:59-68. doi:https://10.1016/j.foodres.2017.10.021

10. Lin K-Y, Edbrooke L, Granger CL, Denehy L, Frawley HC (2019) The impact of gynaecological cancer treatment on physical activity levels: a systematic review of observational studies. Braz J Phys Ther 23 (2):79-92. doi:https://10.1016/j.bjpt.2018.11.007

11. Tollosa DN, Holliday E, Hure A, Tavener M, James EL (2020) Multiple health behaviors before and after a cancer diagnosis among women: A repeated cross-sectional analysis over 15 years. Cancer Med. doi: https://doi.org/10.1002/cam4.2924

12. Lokich E (2019) Gynecologic cancer survivorship. Obstet Gynecol Clin North Am 46 (1):165-178. doi:https://10.1016/j.ogc.2018.10.002

13. Carpenter CJ (2010) A meta-analysis of the effectiveness of health belief model variables in predicting behavior. Health Commun 25 (8):661-669

14. Park CL, Gaffey AE (2007) Relationships between psychosocial factors and health behavior change in cancer survivors: an integrative review. Ann Behav Med 34 (2):115-134. doi:https://10.1007/BF02872667

15. Stanton AL, Rowland JH, Ganz PA (2015) Life after diagnosis and treatment of cancer in adulthood: Contributions from psychosocial oncology research. Am Psychol 70 (2):159. doi:https://10.1037/a0037875

16. Weinstein ND (1988) The precaution adoption process. Health psychol 7 (4):355. doi:https://10.1037//02786133.7.4.355

17. Jim HS, Jacobsen PB (2008) Posttraumatic stress and posttraumatic growth in cancer survivorship: a review. Cancer J 14 (6):414-419. doi:https://10.1097/PPO.0b013e31818d8963

18. Kanera IM, Bolman CA, Mesters I, Willems RA, Beaulen AA, Lechner L (2016) Prevalence and correlates of healthy lifestyle behaviors among early cancer survivors. BMC cancer 16 (1):4. doi:https://10.1186/s12885015-2019-x

19. van Putten M, Husson O, Mols F, Luyer MD, van de Poll-Franse LV, Ezendam NP (2016) Correlates of physical activity among colorectal cancer survivors: results from the longitudinal population-based profiles registry. Support Care Cancer 24 (2):573-583. doi:https://10.1007/s00520-015-2816-4

20. van de Poll-Franse LV, Nicolaije KA, Vos MC, Pijnenborg JM, Boll D, Husson O, Ezendam NP, Boss EA, Hermans $\mathrm{RH}$, Engelhart KC (2011) The impact of a cancer Survivorship Care Plan on gynecological cancer patient and health care provider reported outcomes (ROGY Care): study protocol for a pragmatic cluster randomized controlled trial. Trials 12 (1):256. doi:https://10.1186/1745-6215-12-256

21. Crespi CM, Ganz PA, Petersen L, Castillo A, Caan B (2008) Refinement and psychometric evaluation of the impact of cancer scale. J Natl Cancer Inst 100 (21):1530-1541. doi:https://10.1093/jnci/djn340

22. Bours MJ, Beijer S, Winkels RM, Van Duijnhoven FJ, Mols F, Breedveld-Peters JJ, Kampman E, Weijenberg MP, Van De Poll-Franse LV (2015) Dietary changes and dietary supplement use, and underlying motives for these habits reported by colorectal cancer survivors of the Patient Reported Outcomes Following Initial Treatment 
and Long-Term Evaluation of Survivorship (PROFILES) registry. Br J Nutr 114 (2):286-296.

doi:https://10.1017/S0007114515001798

23. World Cancer Research Fund/American Institute for Cancer Research (2018) Diet, Nutrition, Physical Activity and Cancer: a Global Perspective. Continuous Update Project Expert Report 2018.

24. Van Duijn C, Keij I (2002) Sociaal-economische status indicator op postcode niveau. Maandstatistiek van de bevolking., vol 50. Centraal Bureau voor de Statistiek,

25. Fayers P, Bottomley A, Group EQoL (2002) Quality of life research within the EORTC-the EORTC QLQ-C30. Eur J Cancer 38:125-133. doi:https://10.1016/s0959-8049(01)00448-8

26. Rowlands IJ, Lee C, Janda M, Nagle CM, Obermair A, Webb PM, Group ANECS (2013) Predicting positive and negative impacts of cancer among long-term endometrial cancer survivors. Psychooncology 22 (9):1963-1971. doi:https://10.1002/pon.3236

27. Rock CL, Doyle C, Demark-Wahnefried W, Meyerhardt J, Courneya KS, Schwartz AL, Bandera EV, Hamilton KK, Grant B, McCullough M (2012) Nutrition and physical activity guidelines for cancer survivors. CA Cancer J Clin $62(4): 242-274$

28. Twisk J (2014) Inleiding in de toegepaste biostatistiek, vol 4. Amsterdam: Reed Business Education,

29. Franks HM, Roesch SC (2006) Appraisals and coping in people living with cancer: a meta-analysis. Psychooncology 15 (12):1027-1037. doi:https://10.1002/pon.1043

30. van Broekhoven ME, de Rooij BH, Pijnenborg JM, Vos MC, Boll D, Kruitwagen RF, van de Poll-Franse LV, Ezendam NP (2017) Illness perceptions and changes in lifestyle following a gynecological cancer diagnosis: A longitudinal analysis. Gynecol Oncol 145 (2):310-318. doi:https://10.1016/j.ygyno.2017.02.037

31. Clark LH, Ko EM, Kernodle A, Harris A, Moore DT, Gehrig PA, Bae-Jump V (2016) Endometrial cancer survivors' perceptions of provider obesity counseling and attempted behavior change: are we seizing the moment? Int $\mathrm{J}$ Gynecol Cancer 26 (2):318-324. doi:https://10.1097/IGC.0000000000000596

32. Costanzo ES, Lutgendorf SK, Bradley SL, Rose SL, Anderson B (2005) Cancer attributions, distress, and health practices among gynecologic cancer survivors. Psychosom Med 67 (6):972-980.

doi:https://10.1097/01.psy.0000188402.95398.c0

33. Price J, Barrett-Bernstein M, Wurz A, Karvinen KH, Brunet J (2020) Health beliefs and engagement in moderateto-vigorous-intensity physical activity among cancer survivors: a cross-sectional study. Support Care Cancer. doi:https://doi.org/10.1007/s00520-020-05515-9

34. Durazo A, Cameron LD (2019) Representations of cancer recurrence risk, recurrence worry, and healthprotective behaviours: An elaborated, systematic review. Health Psychol Rev 13 (4):447-476. doi:https://10.1080/17437199.2019.1618725

35. Gillespie C, Goode C, Hackett C, ANDREYEV HN (2007) The clinical needs of patients with chronic gastrointestinal symptoms after pelvic radiotherapy. Aliment Pharmacol Ther 26 (4):555-563. doi:https://doi.org/10.1111/j.1365-2036.2007.03405.x

\section{Tables}

Table 1: Characteristics of the total study population and according to lifestyle change groups. 


\begin{tabular}{|c|c|c|c|c|c|c|c|c|}
\hline & & Dietary beha & ior change & $\mathrm{J}=216)$ & $\begin{array}{l}\text { Physical a } \\
\text { change (N }\end{array}$ & & & \\
\hline & Total & $\begin{array}{l}\text { No } \\
\text { change/ }\end{array}$ & $\begin{array}{l}\text { Eating } \\
\text { healthier }^{\mathrm{a}}\end{array}$ & $\begin{array}{l}\mathrm{p}- \\
\text { value }^{\mathrm{b}}\end{array}$ & $\begin{array}{l}\text { No } \\
\text { change in } \\
\text { physical }\end{array}$ & $\begin{array}{l}\text { Less } \\
\text { physical } \\
\text { activity }\end{array}$ & $\begin{array}{l}\text { More } \\
\text { physical } \\
\text { activity }\end{array}$ & $\begin{array}{l}\text { p- } \\
\text { value }^{b}\end{array}$ \\
\hline & $\mathrm{N}=$ & $\begin{array}{l}\text { eating } \\
\text { unhealthier }\end{array}$ & & & activity & & & \\
\hline & 229 & $\mathrm{~N}=172$ & $\mathrm{~N}=44$ & & $N=133$ & $N=36$ & $N=43$ & \\
\hline Age (years) & & & & 0.87 & & & & $<0.01$ \\
\hline Mean (SD) & $\begin{array}{l}66 \\
(9.5)\end{array}$ & $66(9.9)$ & $66(8.5)$ & & $67(9.0)$ & $67(9.6)$ & $61(9.2)$ & \\
\hline Partner status & & & & 0.97 & & & & 0.07 \\
\hline Partner & 184 & $138(81)$ & $35(81)$ & & 104 (79) & $26(74)$ & $39(93)$ & \\
\hline No partner & (01) & 32 (19) & $8(19)$ & & $28(21)$ & $9(26)$ & $3(7)$ & \\
\hline & $\begin{array}{l}42 \\
(19)\end{array}$ & & & & & & & \\
\hline Educational & & & & & & & & 0.27 \\
\hline Iowe & 29 & $23(14)$ & $4(10)$ & 0.54 & $18(14)$ & $3(9)$ & $4(9)$ & \\
\hline Intormodiat & (I0) & $122(71)$ & $29(69)$ & & $98(74)$ & $23(66)$ & $29(69)$ & \\
\hline Intermediate & $\begin{array}{l}161 \\
(72)\end{array}$ & $26(15)$ & $9(21)$ & & $16(12)$ & $9(26)$ & $9(21)$ & \\
\hline 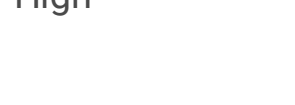 & $\begin{array}{l}35 \\
(16)\end{array}$ & & & & & & & \\
\hline Socio-economic & & & & 0.45 & & & & 0.83 \\
\hline 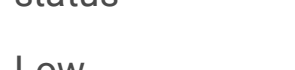 & 37 & $29(18)$ & $4(10)$ & & $22(18)$ & $6(18)$ & $6(14)$ & \\
\hline & & $62(38)$ & $17(42)$ & & $49(39)$ & $14(42)$ & $14(33)$ & \\
\hline Intermediate & $\begin{array}{l}83 \\
(39)\end{array}$ & $71(44)$ & $20(49)$ & & $54(43)$ & $13(39)$ & $22(52)$ & \\
\hline & $\begin{array}{l}94 \\
(44)\end{array}$ & & & & & & & \\
\hline Cancer type & & & & 0.16 & & & & 0.02 \\
\hline Endometrial & 136 & $97(56)$ & $30(68)$ & & $90(68)$ & $17(47)$ & $21(49)$ & \\
\hline Ovarian & & $75(44)$ & $14(32)$ & & $43(32)$ & $19(53)$ & $22(51)$ & \\
\hline & $\begin{array}{l}93 \\
(41)\end{array}$ & & & & & & & \\
\hline Tumor stage & & & & 0.30 & & & & $<0.01$ \\
\hline I & 161 & $123(72)$ & $29(66)$ & & 104 (78) & $18(50)$ & $28(65)$ & \\
\hline III & $10(1)$ & $5(3)$ & $4(9)$ & & $5(4)$ & $2(6)$ & $3(7)$ & \\
\hline IV & $10(4)$ & $35(20)$ & $8(18)$ & & $21(16)$ & $10(28)$ & $9(21)$ & \\
\hline & (19) & $9(5)$ & $3(7)$ & & $3(2)$ & $6(17)$ & $3(7)$ & \\
\hline & $14(6)$ & & & & & & & \\
\hline
\end{tabular}




\begin{tabular}{|c|c|c|c|c|c|c|c|c|}
\hline \multicolumn{9}{|l|}{ Treatment (yes) } \\
\hline Surgery & \multirow{2}{*}{$\begin{array}{l}224 \\
(98)\end{array}$} & $168(98)$ & $44(100)$ & 0.58 & $133(100)$ & $34(94)$ & $43(100)$ & 0.03 \\
\hline Radiotherapy & & 32 (19) & $10(23)$ & 0.54 & $27(20)$ & $9(25)$ & $4(9)$ & 0.16 \\
\hline \multirow[t]{2}{*}{ Chemotherapy } & $\begin{array}{l}45 \\
(20)\end{array}$ & $57(33)$ & $12(27)$ & 0.46 & $31(23)$ & $20(56)$ & $16(36)$ & $<0.01$ \\
\hline & \multicolumn{8}{|l|}{$\begin{array}{l}73 \\
(32)\end{array}$} \\
\hline \multicolumn{4}{|l|}{ Comorbidities } & \multicolumn{4}{|l|}{0.86} & \multirow[t]{5}{*}{0.16} \\
\hline 0 & \multirow{4}{*}{$\begin{array}{l}52 \\
(23) \\
54 \\
(24) \\
119 \\
(53)\end{array}$} & $41(24)$ & $9(22)$ & & $34(26)$ & $4(12)$ & $11(26)$ & \\
\hline 1 & & $39(23)$ & $11(27)$ & & $28(21)$ & $6(18)$ & $13(30)$ & \\
\hline \multirow[t]{2}{*}{$>1$} & & $91(53)$ & $21(51)$ & & $69(53)$ & $24(71)$ & $19(44)$ & \\
\hline & & & & & & & & \\
\hline $\begin{array}{l}\text { Physical } \\
\text { limitations }^{c}\end{array}$ & \multirow[b]{2}{*}{$\begin{array}{l}11.1 \\
(0-20)\end{array}$} & \multirow[b]{2}{*}{$8.3(0-20)$} & \multirow[b]{2}{*}{$\begin{array}{l}8.3(0- \\
22.5)\end{array}$} & \multirow[b]{2}{*}{0.96} & \multirow[b]{2}{*}{$\begin{array}{l}6.7(0- \\
13.3)\end{array}$} & \multirow[b]{2}{*}{$\begin{array}{l}20.0 \\
(10.8- \\
40.0)\end{array}$} & \multirow[b]{2}{*}{$\begin{array}{l}6.7(0- \\
13.3)\end{array}$} & \multirow[b]{2}{*}{$<0.01$} \\
\hline Median (IQR) & & & & & & & & \\
\hline BMI $\left(\mathrm{kg} / \mathrm{m}^{2}\right)$ & & & & 0.12 & & & & 0.78 \\
\hline Median (IQR) & $\begin{array}{l}27.7 \\
(24.2- \\
32.8)\end{array}$ & $\begin{array}{l}28.2(24.3- \\
32.8)\end{array}$ & $\begin{array}{l}25.5 \\
(22.3- \\
33.9)\end{array}$ & & $\begin{array}{l}28.1(24.6- \\
32.8)\end{array}$ & $\begin{array}{l}27.9 \\
(23.7- \\
31.0)\end{array}$ & $\begin{array}{l}27.6 \\
(23.9- \\
34.7)\end{array}$ & \\
\hline Gastrointestinal & \multirow{3}{*}{$\begin{array}{l}65 \\
(30)\end{array}$} & & & \multirow[t]{5}{*}{0.03} & & & & \multirow[t]{5}{*}{$<0.01$} \\
\hline symptoms ${ }^{\mathrm{d}}(\%)$ & & $55(34)$ & $7(16)$ & & $44(36)$ & $2(6)$ & $17(42)$ & \\
\hline $\begin{array}{l}\text { Not suffered } \\
\text { from }\end{array}$ & & $48(30)$ & $21(49)$ & & $36(29)$ & $15(42)$ & $16(39)$ & \\
\hline Suffered from & \multirow{2}{*}{$\begin{array}{l}74 \\
(34) \\
77 \\
(36)\end{array}$} & $57(36)$ & $15(35)$ & & $43(35)$ & $19(53)$ & $8(20)$ & \\
\hline $\begin{array}{l}\text { Still suffering } \\
\text { from }\end{array}$ & & & & & & & & \\
\hline \multirow{2}{*}{$\begin{array}{l}\text { IOCv2 scale } \\
(\text { Mean (SD)) }\end{array}$} & \multirow[b]{2}{*}{$\begin{array}{l}3.59 \\
(1.0)\end{array}$} & & & & & & & \multirow{4}{*}{$\begin{array}{l}<0.01 \\
0.02 \\
<0.01\end{array}$} \\
\hline & & $3.55(1.0)$ & $3.77(0.9)$ & 0.19 & $\begin{array}{l}3.43 \\
(0.92)\end{array}$ & $\begin{array}{l}4.23 \\
(0.67)\end{array}$ & $\begin{array}{l}3.56 \\
(1.09)\end{array}$ & \\
\hline awareness & \multirow{2}{*}{$\begin{array}{l}2.61 \\
(0.8)\end{array}$} & $2.58(0.8)$ & $2.60(0.7)$ & 0.91 & 2.50 & 289 & 2.69 & \\
\hline \multirow{2}{*}{$\begin{array}{l}\text { Meaning of } \\
\text { cancer }\end{array}$} & & $2.23(0.9)$ & $2.13(0.8)$ & 0.54 & $(0.77)$ & $(0.65)$ & $(0.81)$ & \\
\hline & \multirow{2}{*}{$\begin{array}{l}2.24 \\
(0.9)\end{array}$} & $2.83(1.1)$ & $2.92(1.0)$ & 0.60 & 2.14 & 2.68 & 2.17 & $<0.01$ \\
\hline $\begin{array}{l}\text { Appearance } \\
\text { concerns }\end{array}$ & & $2.30(0.8)$ & $2.29(0.7)$ & 0.94 & (0.88) & (0.86) & (1.04) & $<0.01$ \\
\hline Body change & $\begin{array}{l}2.89 \\
(1.1)\end{array}$ & $3.00(1.0)$ & $3.11(0.8)$ & 0.50 & $\begin{array}{l}2.63 \\
(0.98)\end{array}$ & $\begin{array}{l}3.91 \\
(0.78)\end{array}$ & $\begin{array}{l}2.67 \\
(1.11)\end{array}$ & $<0.01$ \\
\hline & 2.33 & & & & 2.14 & 2.99 & 2.32 & \\
\hline $\begin{array}{l}\text { Life } \\
\text { interferences }\end{array}$ & $(0.8)$ & & & & (0.68) & $(0.65)$ & $(0.84)$ & \\
\hline Worry & $\begin{array}{l}3.05 \\
(1.0)\end{array}$ & & & & $\begin{array}{l}2.81 \\
(0.81)\end{array}$ & $\begin{array}{l}3.75 \\
(0.84)\end{array}$ & $\begin{array}{l}3.11 \\
(1.09)\end{array}$ & \\
\hline
\end{tabular}


Note: ${ }^{a}$ Eating healthier according to WCRF dietary recommendations for cancer survivors: more consumption of fruit, vegetables, fibers/wholegrain, less consumption of fat, meat, sugar, alcohol, salt.

${ }^{b}$ p-values: comparison between no change/eating unhealthier vs. eating healthier, comparison between no change vs. less vs. more physical activity according to t-tests, ANOVA, Chi-square, Fisher's Exact tests and Mann Whitney U/Kruskal Wallis-test.

CHigher score refers to more physical limitations.

${ }^{\mathrm{d}}$ Gastrointestinal symptoms: poor appetite, cramps, frequent small amounts of stool, constipation, diarrhea, change in taste and/or smell, aversion, acid indigestion and others.

eHigher score refers to more psychosocial impact (range 1-5). SD=standard deviation. IQR=interquartile range.

Table 2: Associations of cancer-related psychosocial factors with dietary change post-diagnosis among gynecological cancer survivors $(\mathrm{N}=216)$.

\begin{tabular}{|c|c|c|c|c|}
\hline \multirow{3}{*}{ IOCv2 scale (1-5) } & \multicolumn{4}{|l|}{ Eating healthier } \\
\hline & \multicolumn{2}{|c|}{$\begin{array}{l}\text { Adjusted for socio-demographic } \\
\text { /clinical confounders }\end{array}$} & \multicolumn{2}{|c|}{$\begin{array}{l}\text { Adjusted for socio-demographic/ } \\
\text { clinical confounders and GI symptoms }\end{array}$} \\
\hline & OR $(95 \% \mathrm{Cl})$ & p-value & OR $(95 \% \mathrm{Cl})$ & p-value \\
\hline Health awareness & $1.27(0.87 ; 1.86)$ & $0.21^{a, b}$ & $1.07(0.71 ; 1.61)$ & $0.75^{\mathrm{a}, \mathrm{b}, \mathrm{e}}$ \\
\hline Meaning of cancer & $0.94(0.59 ; 1.49)$ & $0.80^{c, d}$ & $0.86(0.53 ; 1.39)$ & $0.53^{c, d, e}$ \\
\hline Appearance concerns & $1.03(0.69 ; 1.54)$ & $0.87^{a, b}$ & $0.92(0.60 ; 1.41)$ & $0.69^{a, b, e}$ \\
\hline Body change concerns & $1.18(0.85 ; 1.64)$ & $0.32^{b, c}$ & $1.00(0.69 ; 1.46)$ & $1.00^{b, c, e}$ \\
\hline Life interferences & $1.01(0.62 ; 1.65)$ & $0.97^{b, d}$ & * & * \\
\hline Worry & $1.19(0.80 ; 1.75)$ & $0.39^{a, b}$ & $0.96(0.63 ; 1.48)$ & $0.86^{\mathrm{a}, \mathrm{b}, \mathrm{e}}$ \\
\hline
\end{tabular}

Note: Confounders: ${ }^{a}$ socio-economic status, ${ }^{b}$ type of cancer, ${ }^{c} \mathrm{BMI},{ }^{d}$ tumor stage, ${ }^{e}$ gastrointestinal symptoms (GI). Confounders' selection was based on relevant change in regression coefficient ( $>10 \%)$ (2 most relevant confounders were added to the model) and a priori selection (gastrointestinal symptoms).

*not adjusted for gastrointestinal symptoms as the content of the scale includes complaints as a consequence of cancer(treatment).

Table 3: Associations of cancer-related psychosocial factors with physical activity change post-diagnosis among gynecological cancer survivors $(\mathrm{N}=212)$. 


\begin{tabular}{|c|c|c|c|c|c|c|c|c|}
\hline \multirow{3}{*}{$\begin{array}{l}\text { IOC v2 Scale } \\
(1-5)\end{array}$} & \multicolumn{4}{|c|}{ Less physical activity } & \multicolumn{4}{|c|}{ More physical activity } \\
\hline & \multicolumn{2}{|c|}{$\begin{array}{l}\text { Adjusted for socio- } \\
\text { demographic/clinical } \\
\text { confounders }\end{array}$} & \multicolumn{2}{|c|}{$\begin{array}{l}\text { Adjusted for socio- } \\
\text { demographic/clinical } \\
\text { confounders, GI } \\
\text { symptoms and/or } \\
\text { physical limitations }\end{array}$} & \multicolumn{2}{|c|}{$\begin{array}{l}\text { Adjusted for socio- } \\
\text { demographic/clinical } \\
\text { confounders }\end{array}$} & \multicolumn{2}{|c|}{$\begin{array}{l}\text { Adjusted for socio- } \\
\text { demographic/clinical } \\
\text { confounders, GI } \\
\text { symptoms and/or } \\
\text { physical limitations }\end{array}$} \\
\hline & $\begin{array}{l}\mathrm{OR}(95 \% \\
\mathrm{Cl})\end{array}$ & $\begin{array}{l}\mathrm{p}- \\
\text { value }\end{array}$ & $\begin{array}{l}\mathrm{OR}(95 \% \\
\mathrm{Cl})\end{array}$ & $\mathrm{p}$-value & $\begin{array}{l}\mathrm{OR}(95 \% \\
\mathrm{Cl})\end{array}$ & $\begin{array}{l}\mathrm{p}- \\
\text { value }\end{array}$ & $\begin{array}{l}\mathrm{OR}(95 \% \\
\mathrm{Cl})\end{array}$ & $\mathrm{p}$-value \\
\hline $\begin{array}{l}\text { Health } \\
\text { awareness }\end{array}$ & $\begin{array}{l}3.71(2.01 ; \\
6.86)\end{array}$ & $<0.01^{\mathrm{a}}$ & $\begin{array}{l}2.79 \\
(1.38 ; \\
5.65)\end{array}$ & $<0.01^{\mathrm{a}, \mathrm{f}, \mathrm{g}}$ & $\begin{array}{l}1.00(0.67 ; \\
1.49)\end{array}$ & $0.68^{e}$ & $\begin{array}{l}0.98 \\
(0.61 ; \\
1.57)\end{array}$ & $0.92^{e, f, g}$ \\
\hline $\begin{array}{l}\text { Meaning of } \\
\text { cancer }\end{array}$ & $\begin{array}{l}1.85(1.07 ; \\
3.18)\end{array}$ & $0.03^{b}$ & $\begin{array}{l}1.43 \\
(0.75 \\
2.73)\end{array}$ & $0.28^{\mathrm{b}, \mathrm{fg}}$ & $\begin{array}{l}1.09(0.86 ; \\
1.38)\end{array}$ & $0.49^{\mathrm{e}}$ & $\begin{array}{l}1.59 \\
\text { (0.91; } \\
2.77)\end{array}$ & $0.10^{e, f, g}$ \\
\hline $\begin{array}{l}\text { Appearance } \\
\text { concerns }\end{array}$ & $\begin{array}{l}1.65(1.10 \\
2.47)\end{array}$ & $0.01^{c}$ & $\begin{array}{l}1.31 \\
\text { (0.81; } \\
2.13)\end{array}$ & $0.27^{\mathrm{c}, \mathrm{fg}}$ & $\begin{array}{l}0.94(0.62 ; \\
1.41)\end{array}$ & $0.75^{c}$ & $\begin{array}{l}0.78 \\
(0.48 \\
1.26)\end{array}$ & $0.32^{\mathrm{c}, \mathrm{fg} g}$ \\
\hline $\begin{array}{l}\text { Body } \\
\text { change } \\
\text { concerns }\end{array}$ & * & * & $\begin{array}{l}3.04 \\
(1.71 ; \\
5.39)\end{array}$ & $<0.01^{f, g}$ & $\begin{array}{l}0.98(0.68 ; \\
1.39)\end{array}$ & $0.90^{\mathrm{b}}$ & $\begin{array}{l}0.86 \\
(0.54 ; \\
1.37)\end{array}$ & $0.53^{b, f, g}$ \\
\hline $\begin{array}{l}\text { Life } \\
\text { interferences }\end{array}$ & $\begin{array}{l}3.98(2.17 \\
7.32)\end{array}$ & $<0.01^{d}$ & $\begin{array}{l}4.88 \\
(2.29 \\
10.38)\end{array}$ & $<0.01^{\mathrm{d}, \mathrm{g}}$ & $\begin{array}{l}1.24(0.75 ; \\
2.07)\end{array}$ & $0.40^{b, c}$ & $\begin{array}{l}1.42 \\
(0.77 ; \\
2.61)\end{array}$ & $0.26^{b, c, g}$ \\
\hline Worry & $\begin{array}{l}2.92(1.74 ; \\
4.89)\end{array}$ & $<0.01^{d}$ & $\begin{array}{l}2.62 \\
(1.42 ; \\
4.85)\end{array}$ & $<0.01^{\mathrm{d}, \mathrm{f}, \mathrm{g}}$ & $\begin{array}{l}1.36(0.91 ; \\
2.02)\end{array}$ & $0.13^{c}$ & $\begin{array}{l}1.24 \\
\text { (0.77; } \\
1.99)\end{array}$ & $0.38^{c, f, g}$ \\
\hline
\end{tabular}

Note: Confounders: ${ }^{a}$ BMI, ${ }^{b}$ tumor stage, ${ }^{c}$ type of cancer, ${ }^{d}$ chemotherapy, ${ }^{e}$ age, ${ }^{f}$ gastrointestinal symptoms, ${ }^{g}$ physical limitations. Confounders' selection was based on relevant change in regression coefficient $(>10 \%)(2$ most relevant confounders were added to the model) and a priori selection (gastrointestinal symptoms, physical limitations).

*no socio-demographic or clinical factors were identified as relevant confounders.

\section{Supplementary Files}

This is a list of supplementary files associated with this preprint. Click to download.

- ESM1.pdf

- ESM2.pdf

- ESM3.pdf

- ICMJEBR.pdf

- ICMJEKD.pdf

- ICMJEM.Hoedjes.pdf

- ICMJEMCVos.pdf

- ICMJENE.pdf 
- ICMJEPijnenborg.pdf

- ICMJESBeijer.pdf

- ICMJEboll.pdf 